\title{
ASSOCIATION BETWEEN CELL PHONE RESTRICTIONS AND TEENS' SELF-REPORTED CELL PHONE USE WHILE DRIVING
}

\author{
Johnathon Ehsani, Bruce G. Simons-Morton, Jessamyn G. Perlus, Yunlong Xie, \\ and Paul S. Albert \\ Eunice Kennedy Shriver National Institute of Child Health and Human Development \\ Bethesda, MD, USA \\ Email: johnathon.ehsani@nih.gov
}

\begin{abstract}
Summary: The purpose of this study was to describe the association between a range of cell phone restrictions and self-reported cell phone use while driving among teen drivers. Methods: U.S. high school students $(\mathrm{N}=780)$ from 14 states completed questionnaires, including items on cell phone use while driving. Cell phone restrictions for each state were identified using the Public Health Law Research Distracted Driving Law database and divided into five categories. Associations between cell phone restrictions and self-reported cell phone use while driving were estimated as odds ratios, adjusting for driving exposure. Results: In states with cell phone restrictions, teens were less likely to report talking or texting while driving, relative to teens in states with no restrictions. Talking and texting while driving were significantly less likely in states with texting restrictions for all drivers. All driver texting restrictions combined with teen hand-held phone restrictions were significantly associated with lower texting but not talking while driving. Conclusions: The presence of restrictions appears to be better than no restrictions with respect to self-reported teen cell phone use. Further research is needed to determine whether restrictions applying exclusively to teen drivers or restrictions for all drivers provide the greatest safety benefit.
\end{abstract}

\section{INTRODUCTION}

Teen drivers' greater willingness to engage in cell phone use while driving relative to other drivers (Tison, Chaudhary et al. 2011), and the widespread adoption of smartphones that allow internet browsing (Neilsen 2013), suggests that cell phone-related driver distraction in this population is likely to remain a source of crash risk (Klauer, Guo et al. 2014). To date, 40 states have passed legislation restricting cell phone use for 16- and 17-year-old drivers, and 14 states have restricted hand-held cell phone use for all drivers (Insurance Institute for Highway Safety 2014).Current approaches to limiting cell phone use while driving include restricting specific behaviors (e.g. texting, hand-held, or any cell phone use) according to the driver age (e.g. younger than 18-years or all drivers) or stage of licensure (e.g. learner permit and intermediate license). However, little is understood about how these restrictions influence teen driver behavior, and which are most effective at reducing cell phone use while driving.

A previous self-report survey study (Braitman and McCartt 2010) on the impact of restriction types on driver behavior had mixed findings. Drivers in states with an all-driver hand-held restriction, banning the physical use of the phone while driving, had a significantly lower percentage of hand-held cell phone use while driving, relative to drivers in states where the ban was not in effect. However, there was no association between the presence of any texting 
restrictions and texting while driving . The study failed to include drivers aged 16- and 17-years. Due to their inexperience, drivers of this age experience the peak of lifetime crash risk (Mayhew, Simpson et al. 2003), and are the population for which the majority of cell phone restrictions apply (Ibrahim, Anderson et al. 2011).

The purpose of this study was to describe the association between four categories of cell phone restrictions and the likelihood of talking and texting while driving among teen drivers in the $11^{\text {th }}$ grade, the age when most adolescents are first eligible to receive a license to drive independently.

\section{METHODS}

\section{Sampling}

Data were from the second annual wave of a national cohort of high school students from the NEXT Generation Health Study (Li 2014). The first wave began when participants were in $10^{\text {th }}$ grade (2009-2010). Primary-sampling units consisted of school districts or groups of school districts stratified across the nine U.S. Census divisions. Within this sampling framework, 137 schools were randomly selected and formally recruited; 80 (58.4\%) agreed to participate. Tenthgrade classes within each recruited school were randomly sampled, and 3,796 students were recruited to participate in the first wave. Youth assent and parental consent were obtained from 2,619 students (69.0\%). Of those who consented, 2,524 completed the Wave 1 (baseline) survey, for an overall completion rate of $66.5 \%$. African American students were oversampled to improve the population estimate.

For Wave 2 of the NEXT Generation Health Study, participants completed questionnaires in the spring of $11^{\text {th }}$ grade (February - May, 2011). Students were given the opportunity to complete the survey online; if they were unable to do so, a hard copy was completed at school when a research staff member visited the school. For the second wave, an additional school district was added to the sample bringing the total number of participants from 2,524 to 2,784. The response rate in Wave 2 was $96.9 \%$. Students received $\$ 45$ for participating in the study at Wave 2 . The Institutional Review Board of the Eunice Kennedy Shriver National Institute of Child Health and Human Development approved the study protocol.

The NEXT study included 22 states in the original sample: California, Colorado, Connecticut, Florida, Georgia, Idaho, Illinois, Kentucky, Louisiana, Massachusetts, Michigan, Minnesota, Nevada, New York, Ohio, Oregon, Pennsylvania, South Dakota, Tennessee, Texas, West Virginia and Wisconsin. To examine the association between cell phone restrictions and selfreported cell phone use while driving, the analyses were restricted to states with 25 or more licensed drivers at Wave 2. This excluded Colorado, Connecticut, Idaho, Michigan, Minnesota, Nevada, New York, and Oregon, and reduced the sample to 14 states. The final sample consisted of 780 participants that reported being licensed for independent, unsupervised driving.

\section{Dependent variable}


The dependent variable was the proportion of days participants reported cell phone use while driving in the last 30 days, relative to the number of days a vehicle was driven in the last 30 days. Respondents answered the question "On how many days in the last 30 days did you drive a vehicle?" Cell phone use while driving was measured using four items: On how many days in the last 30 days while driving have you (a) answered a call on your cell phone, (b) made a call on your cell phone, (c) read text messages, and (d) sent text messages. Responses ranged from 0 to 30 for each item. The proportion was calculated by dividing the number of days a cell phone was used while driving, by the number of days a vehicle was driven.

\section{Independent variables}

Driving exposure. Driving exposure was estimated using a self-reported measure of miles driven: "On average, about how many miles did you drive each day you drove?" This measure of driving exposure is distinct from the number of days driven, as it accounts for the distance traveled and the time spent in the vehicle. Sixteen participants were eliminated as outliers, as they reported driving more than 150 miles per day.

Cell phone restrictions. The presence of driving restrictions in effect during the survey period (February - May, 2011) was determined using the Public Health Law Research Distracted Driving Law database (Ibrahim, Anderson et al. 2011) cross checked with the Highway Loss Data Institute database from the Insurance Institute for Highway Safety (Insurance Institute for Highway Safety 2014). Restrictions were coded as applying exclusively to novice teenage drivers (teen-only) or applying to drivers of all ages (including teen drivers). Restrictions were further classified as applying only to texting while driving, or for hand-held cell phone use. Hand-held restrictions prohibit manipulation of a cell phone while driving, including both talking and texting. The presence of hands-free restrictions was not assessed. States were grouped into five categories according to the restrictions: (1) no restrictions; (2) teen driver hand-held restriction; (3) teen driver hand-held restriction AND all driver texting restriction; (4) all driver texting restriction; and (5) all driver hand-held restriction. Primary enforcement was in effect for all cell phone restrictions for states in the sample, meaning police officers could stop drivers solely on the basis of non-compliance with the cell phone restrictions.

\section{Statistical Analysis}

Of primary scientific interest was examining the association between state cell phone restrictions and self-reported cell phone use (making a call, answering a call, reading a text message, sending a text message) in the study population. Specifically, the prevalence of cell phone use (on a daily basis over 30 days of measurement) was compared between states with no restrictions and states with varying types of restrictions. To account for heterogeneity in these rates across states, we used Generalized Estimating Equations (GEE) (Liang and Zeger 1986) with a logistic link and a grouped binomial outcome. The number of days a cell phone was used while driving in the last 30 days were classified as events, and the number of days participants reported driving in the last 30 days were classified as trials. The GEE methodology accounts for state-specific variation as well as over-dispersion in frequency counts (i.e., more variation than is possible with a binomial assumption). This analysis was done with and without adjustments for driving exposure, measured as the number of miles driven. The robust variance estimator 
was used under the assumption of an independence-working model for statistical inference. The magnitude of the effect of restrictions was estimated as odds ratios adjusting for participants' driving exposure. Differences in cell phone use while driving for the entire sample were tested using the ANOVA Test for Equality of All Means. Where significant differences were detected, Tukey's Studentized Range Test was used to conduct pairwise comparisons between categories. Statistical analyses were performed using SAS 9.3 (Statistical Analysis Software (SAS) 2010).

\section{RESULTS}

The average age of the sample was 17.4 years (standard deviation (SD) .51 ), and $47.6 \%$ of participants were male. On average, participants reported driving 23 of the previous 30 days (SD 9.07, median 28) and approximately 21 miles each day they drove (SD 19.35, median 15). Participants' overall cell phone use while driving is described in Table 1. Participants reported reading a text message on a significantly higher number of days than answering a call or making a call while driving. Similarly, the number of days participants reported sending a text was significantly higher than the number of days they made a call while driving. Of the 14 states included in the sample, 10 had a cell phone restriction in effect during the survey period.

Table 1. Frequency of Cell Phone Use While Driving (\# days in the past 30 days)

\begin{tabular}{cclc}
\hline Type of Cell Phone Use While Driving & Range & Mean & SD \\
\hline Answered Call & $0-30$ & $8.46^{\mathrm{a}}$ & 9.70 \\
Made Call & $0-30$ & $7.37^{\mathrm{a}, \mathrm{b}}$ & 9.47 \\
Read Text & $0-30$ & 10.58 & 11.38 \\
Sent Text & $0-30$ & 9.49 & 11.36 \\
\hline SD = Standard Deviation; ${ }^{\mathrm{a}}$ Significantly lower than read text message \\
\begin{tabular}{l}
$(p<.05){ }^{\mathrm{b}}$ Significantly lower than sent text $(p<.05)$ \\
\hline
\end{tabular}
\end{tabular}

After adjusting for driving exposure, the presence of cell phone restrictions was associated with lower odds of talking and texting while driving. The magnitude of the association varied according to the type of restriction in effect, and specific cell phone use behaviors (Table 2). Specifically, teens were significantly less likely to report talking or texting while driving when texting restrictions for all drivers were in effect. The magnitude of the association was strongest with texting while driving, although both talking and texting were significantly lower in states with all driver texting restrictions.

All driver texting restrictions combined with teen hand-held restrictions were also significantly associated with lower texting but not with talking while driving. The adjusted odds of talking or texting while driving was lower in states with teen hand-held restrictions or all driver hand-held restrictions, but not significantly, compared to states with no restrictions in effect.

\section{DISCUSSION}

The purpose of this paper was to examine the association between different cell phone restrictions and teenage driver behavior. Using a cross-sectional study design and data from a sample of drivers in the $11^{\text {th }}$ grade, we examined the association between four types of cell 
phone restrictions on talking and texting while driving. Texting and talking were lower in states with restrictions of any sort, but the strongest associations were observed in states where restrictions apply to all drivers for texting restrictions, or a combination of teen hand-held restrictions and all driver texting restrictions. The absence of an association between teen driver cell phone use and all driver hand-held restrictions was unexpected. These are the most restrictive policies for limiting cell phone use because they confirm normative expectations and consequences for all drivers. This type of restriction may have been adopted in states where the prevalence of cell phone use while driving was already high, which may limit the possibility of detecting a cross-sectional association.

There was considerably greater variability in cell phone use in states with teen-directed restrictions relative to all-driver restrictions. While the strongest association was observed for the all-driver texting restrictions, the results for the teen hand-held restriction achieved a similar magnitude but did not reach statistical significance, possibly due to a smaller sample size. Taken collectively, these findings suggest the presence of driver restrictions is more effective than their absence in reducing teen drivers' cell phone use and distraction. However, it could not be determined whether restrictions that apply exclusively to teen drivers or restrictions for all drivers provide the greatest reduction in teenage drivers' cell phone use while driving. Cell phone restrictions were not introduced according to experimental conditions, and states differ from one another in ways that could influence the outcomes. While we adjusted the analyses for the number of miles driven to account for regional differences in driving exposure (U.S. Department of Transportation 2015), there may be other state-level differences that were unaccounted for such as the likelihood of states to adopt legislation, and the population's willingness to conform with laws (Erikson, Wright et al. 1994)

In this study, the number of states differed according to each restriction type, and various categories of cell phone restrictions are nested within very few states. For example, Wisconsin was the only state in the sample with an all-driver texting restriction. The resulting effect estimates are likely to be imprecise and may be less generalizable to the entire group of states that have this type of restriction. This may also limit the generalizability of the overall results given that sample included less than half of all states that had some form of cell phone restriction. An additional difficulty in addressing policy questions using cross-sectional data means that these findings are associations, and not causal relationships. Future studies, with appropriate sampling protocols, combined with observational methods and long-term follow-up are best suited to definitively answer this question. Hand-held restrictions prohibit cell phone use that requires the manipulation of a cell phone while driving, including talking and texting.

Self-reported measures of cell phone use while driving, rather than objective measures, were used to examine the association between restrictions and behavior. While self-reported measures are a widely used for assessing the cell phone use, it is a limitation of this study. Self-reported cell phone use while driving may be influenced by the presence of legal restrictions. Furthermore, this study did not distinguish between hands-free or hand-held cell phone use while driving, an omission that could have implications for understanding the effect of cell phone restrictions on teenage drivers' cell phone use while driving. The findings of this study are consistent with an effect of policy restrictions on cell phone use while driving and indicate that the presence of any restriction appears to be associated with lower self-reported cell phone 
use while driving among teenagers. However, it could not be determined whether restrictions applying exclusively to teen drivers or restrictions for all drivers provide the greatest benefit.

\section{ACKNOWLEDGEMENT}

This project (contract number HHSN267200800009C) was supported in part by the intramural research program of the Eunice Kennedy Shriver National Institute of Child Health and Human Development (NICHD), and the National Heart, Lung and Blood Institute (NHLBI), the National Institute on Alcohol Abuse and Alcoholism (NIAAA), and Maternal and Child Health Bureau (MCHB) of the Health Resources and Services Administration (HRSA), with supplemental support from the National Institute on Drug Abuse (NIDA).

\section{REFERENCES}

Braitman, K. A. and A. T. McCartt (2010). "National Reported Patterns of Driver Cell Phone Use in the United States." Traffic Injury Prevention 11(6): 543-548.

Erikson, R. S., G. C. Wright and J. P. McIver (1994). Statehouse Democracy: Public Opinion and Policy in the American States, Cambridge University Press.

Ibrahim, J. K., E. D. Anderson, S. C. Burris and A. C. Wagenaar (2011). "State Laws Restricting Driver Use of Mobile Communications Devices: Distracted-Driving Provisions, 1992 - 2010." American Journal of Preventive Medicine 40(6): 659-665.

Insurance Institute for Highway Safety. (2014). "State Laws: Cellphones and Texting September 2014." Retrieved 20th September, 2014, from http://www.iihs.org/iihs/topics/laws/cellphonelaws?topicName=distracted-driving.

Klauer, S. G., F. Guo, B. G. Simons-Morton, M. C. Ouimet, S. E. Lee and T. A. Dingus (2014). "Distracted Driving and Risk of Road Crashes among Novice and Experienced Drivers." New England Journal of Medicine 370(1): 54-59.

Li, K. (2014). "Drinking and parenting practices as predictors of impaired driving behaviors among US adolescents." Journal of studies on alcohol and drugs 75(1): 5.

Liang, K. Y. and S. L. Zeger (1986). "Longitudinal data analysis using generalized linear models." Biometrika 73(1): 13-22.

Mayhew, D. R., H. M. Simpson and A. Pak (2003). "Changes in collision rates among novice drivers during the first months of driving. ." Accident Analysis and Prevention 35: 683691.

Neilsen. (2013). "Ring the bells: More smartphones in students' hands ahead of back-to-school season." Retrieved 2nd December, 2014, from http://www.nielsen.com/us/en/newswire/2013/ring-the-bells-more-smartphones-instudents-hands-ahead-of-back.html.

Statistical Analysis Software (SAS) (2010). Version 9.3. Cary, NC, SAS Institute Inc.

Tison, J., N. Chaudhary and L. Cosgrove (2011). National phone survey on distracted driving attitudes and behaviors. National Highway Traffic Safety Administration. Washington, DC. DOT HS 811555.

U.S. Department of Transportation. (2015). "State and Urbanized Area Statistics." Retrieved 3rd March, 2015, from http://www.fhwa.dot.gov/ohim/onh00/onh2p11.htm. 
Table 2. Adjusted odds ratios of teenage driver cell phone use while driving in the presence of restrictions, relative to use by teenage drivers in states where no restrictions were in effect

\begin{tabular}{|c|c|c|c|c|c|c|c|c|c|c|c|c|}
\hline \multirow[b]{2}{*}{ Unadjusted } & \multicolumn{3}{|c|}{$\begin{array}{l}\text { Teen Hand-held } \\
\text { Restriction } \\
(\mathrm{n}=50)\end{array}$} & \multicolumn{3}{|c|}{$\begin{array}{c}\text { Teen Hand-held } \\
\text { Restriction \& } \\
\text { All Driver Texting } \\
\text { Restriction } \\
(\mathrm{n}=156) \\
\end{array}$} & \multicolumn{3}{|c|}{$\begin{array}{l}\text { All Driver texting Restriction } \\
\qquad(\mathrm{n}=113)\end{array}$} & \multicolumn{3}{|c|}{$\begin{array}{l}\text { All Driver Hand-held } \\
\text { Restrictions } \\
(\mathrm{n}=188)\end{array}$} \\
\hline & OR & & $\mathrm{CI}$ & \multirow[t]{2}{*}{ OR } & \multicolumn{2}{|c|}{$95 \% \mathrm{CI}$} & \multirow[t]{2}{*}{ OR } & \multicolumn{2}{|c|}{$95 \% \mathrm{CI}$} & \multirow[t]{2}{*}{ OR } & \multicolumn{2}{|c|}{$\begin{array}{r}95 \% \\
\text { CI }\end{array}$} \\
\hline \multicolumn{10}{|l|}{ Talking } & & & \\
\hline Answered call & 0.68 & 0.31 & 1.47 & 1.06 & 0.59 & 1.91 & $0.64 * *$ & 0.49 & 0.84 & 1.38 & 0.97 & 1.94 \\
\hline Made call & 0.81 & 0.34 & 1.94 & 1.06 & 0.58 & 1.93 & $0.65 * * *$ & 0.51 & 0.83 & 1.37 & 0.92 & 2.06 \\
\hline \multicolumn{13}{|l|}{ Texting } \\
\hline Read text & 0.52 & 0.24 & 1.11 & 0.73 & 0.50 & 1.05 & $0.42 * * *$ & 0.31 & 0.57 & 0.93 & 0.61 & 1.41 \\
\hline Sent text & 0.55 & 0.26 & 1.14 & 0.77 & 0.50 & 1.18 & $0.39 * * *$ & 0.27 & 0.55 & 1.00 & 0.62 & 1.63 \\
\hline \multicolumn{13}{|c|}{ Adjusted for Driving Exposure } \\
\hline \multicolumn{13}{|c|}{ Talking } \\
\hline Answered call & 0.56 & 0.23 & 1.35 & 0.93 & 0.58 & 1.49 & $0.64 * * *$ & 0.50 & 0.81 & 1.24 & 0.96 & 1.61 \\
\hline Made call & 0.68 & 0.25 & 1.82 & 0.94 & 0.57 & 1.55 & $0.65 * * *$ & 0.52 & 0.81 & 1.24 & 0.91 & 1.71 \\
\hline \multicolumn{13}{|l|}{ Texting } \\
\hline Read text & 0.44 & 0.18 & 1.05 & $0.65 *$ & 0.47 & 0.90 & $0.41 * * *$ & 0.31 & 0.56 & 0.84 & 0.59 & 1.19 \\
\hline Sent text & 0.46 & 0.19 & 1.07 & $0.68 *$ & 0.47 & 0.98 & $0.38 * * *$ & 0.27 & 0.53 & 0.91 & 0.60 & 1.36 \\
\hline
\end{tabular}

Notes. $\mathrm{OR}=$ odds ratio, $\mathrm{CI}=$ Confidence intervals, $p<.05^{*}, p<.01 * *, p<.001 * * *$

$\mathrm{nb}$. Hand-held restrictions prohibit cell phone use that requires the manipulation of a cell phone while driving, including talking and texting 